\title{
DISPOSIÇÃO IRREGULAR DOS RESÍDUOS SÓLIDOS URBANOS E SUAS INFLUÊNCIAS NA SAÚDE PÚBLICA NO MUNICÍPIO DE MUCAJAÍ - RR
}

\author{
Irregular disposal of urban solid waste and its influences in public health in \\ Mucajaí Municipality - RR.
}

\author{
Franciene Cruz da Silva \\ Graduada em Biologia pela Universidade Estadual de Roraima \\ francienecruz5@gmail.com \\ Márcia Teixeira Falcão \\ Professora Doutora do Departamento de Geografia da UERR \\ marciafalcao.geog@uerr.edu.br
}

Sandra Kariny Saldanha de Oliveira Professora Doutora do Curso de Biologia da Universidade Estadual de Roraima marciatfalcao@oi.com.br

Renan Bruno Vieira do Vale Graduado em Geografia pela Universidade Estadual de Roraima renanbrunovieira dovale@hotmail.com

Haroldo Scacabarossi Professor Mestre do Curso de Geografia da Universidade Estadual de Roraima haroldogeo@yahoo.com.br

\begin{abstract}
RESUMO: O presente trabalho teve como objetivo demonstrar a influência da disposição irregular dos resíduos sólidos urbanos no ambiente como consequência para o meio natural e a saúde da população da sede do município de Mucajaí/RR. A metodologia adotada se pautou em levantamento bibliográfico pertinente à temática e visitas in loco para verificar a situação na área de disposição final dos resíduos sólidos da cidade. Os resultados da pesquisa demonstraram que os resíduos sólidos urbanos produzidos e coletados são dispostos em uma área urbana da sede do município com características de lixão, localizada a $1,6 \mathrm{~km}$ da sede do município, desencadeando riscos à saúde pública, considerando uma possível contaminação do solo e da água, bem como a proliferação de vetores transmissores de doenças que afetam diretamente a qualidade de vida da população. Diante disso, é necessário que o poder público, juntamente com a sociedade, adote medidas que possam mitigar a destinação correta para os resíduos sólidos urbanos da sede do município de Mucajaí/RR, pautadas na legislação abrangente de proteção ao meio ambiente quanto à especificidade que trata da Política Nacional de Resíduos Sólidos.
\end{abstract}

Palavras-chave: Resíduos sólidos urbanos. Impactos ambientais. Disposição irregular.

ABSTRACT: The present work had the objective of demonstrating the influence of the irregular disposition of the solid urban waste in the environment as a consequence for the environment and the health of the population of the headquarters of the municipality of Mucajaí / RR. The methodology adopted was based on a bibliographical survey pertinent to the theme and on-site visits to verify the situation in the final disposal area of the city's solid waste. The results of the research showed that the municipal solid waste produced and collected is disposed in an urban area of the county seat with characteristics of a dump, located $1.6 \mathrm{~km}$ from the municipality's headquarters, causing risks to public health and possible contamination soil and water, as well as the proliferation of vectors transmitting 
DISPOSIÇÃO IRREGULAR DOS RESÍDUOS SÓLIDOS URBANOS E SUAS INFLUÊNCIAS NA SAÚDE PÚBLICA NO MUNICÍPIO DE MUCAJAÍ - RR

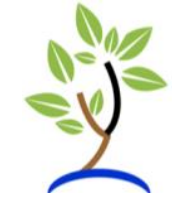

diseases that directly affect the quality of life of the population. Given this, it is necessary that the public power, together with society, adopt measures that can mitigate the correct destination for municipal solid waste of the municipality of Mucajaí / RR, based on the comprehensive legislation protecting the environment as to the specificity that the National Policy on Solid Waste

Key words: Solid urban waste. Environmental impacts. Irregular disposal.

\section{INTRODUÇÃO}

O crescimento desenfreado da população urbana, aliado a não observação dos parâmetros socioambientais ocasionam diversos problemas, muito deles relacionados diretamente com a poluição do meio ambiente. "Acredita-se, por exemplo, que os seres humanos, ao se concentrarem em um determinado espaço físico, aceleram inexoravelmente os processos de degradação ambiental" (COELHO, p. 20, 2012).

Seguindo o pensamento acima se observa que, ao mesmo tempo em que a concentração populacional cresce, a degradação ambiental aumenta. Analisando pelo senso comum o ser humano sempre está em busca de transformações, inovações e curiosidades, sempre aderindo a novas técnicas para alcançar seus objetivos.

Com o avanço tecnológico e o surgimento de novas ferramentas de trabalho, o que se espera de uma sociedade é que ela cresça e se desenvolva cada vez mais. No entanto, hoje o que se vê são os países em desenvolvimento constante, e o processo ininterrupto de degradação da natureza através da diminuição do meio natural que, por sua vez, ocasiona o desequilíbrio ecológico.

$\mathrm{Na}$ sociedade contemporânea, um dos grandes problemas são a geração e a disposição de rejeitos, pois na maioria das cidades os resíduos são depositados de maneira incorreta, considerada assim, uma questão de saúde pública, que abrange todas as classes sociais, trazendo consequências e danos irreparáveis para o ambiente, prejudicando a sociedade em todos os aspectos.

Dessa forma, os resíduos sólidos urbanos alocados de forma inadequada podem desencadear várias espécies de vetores, grandes contribuintes para a infestação de doenças, podendo haver epidemias com o aumento de número de casos de dengue, zika, chicungunha e outras, propiciando um agravamento na qualidade de vida das pessoas.

O presente trabalho tem como objetivo demonstrar a influência da disposição irregular dos resíduos sólidos urbanos no ambiente como consequência negativa para o ambiente e a saúde da população da sede do município de Mucajaí/Roraima.

\section{Conceitos, classificação e disposição dos resíduos sólidos}

O Brasil diariamente gera uma grande quantidade de resíduos sólidos urbanos, cerca de 214 mil toneladas, prejudicando corpos d'água, solo e o ar, além disso, esses oferecem riscos para a saúde da população (ABRELPE, 2016). "Isto porque os resíduos são materiais e substâncias que, depois de utilizados, se não tiverem 
DISPOSIÇÃO IRREGULAR DOS RESÍDUOS SÓLIDOS URBANOS E SUAS INFLUÊNCIAS NA SAÚDE PÚBLICA NO MUNICÍPIO DE MUCAJAÍ - RR

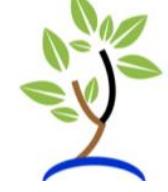

destinação adequada podem pôr em risco as atividades que venham a ser desenvolvidas onde foram dispensados" (GRANZIERA, 2009).

A Presidência da República estabeleceu, em 2 de agosto de 2010, a Política Nacional de Resíduos Sólidos (PNRS) por meio da Lei nํㅜ 12.305 que define resíduos sólidos em seu art. 3ํㅡ, inciso XVI:

Resíduos sólidos: material, substância, objeto ou bem descartado resultante de atividades humanas em sociedade, a cuja destinação final se procede, se propõe proceder ou se está obrigado a proceder, nos estados sólido ou semissólido, bem como gases contidos em recipientes e líquidos cujas particularidades tornem inviável o seu lançamento na rede pública de esgotos ou em corpos d'água, ou exijam para isso soluções técnicas ou economicamente inviáveis em face da melhor tecnologia disponível.

Na verdade, aquilo que é matéria, objeto ou substância que após o uso é descartado passa a não ter utilidade para o fim que foi gerado, tornando-se lixo ou resíduos. Tenório e Espinosa (2004, p.157) ditam que "os conceitos de resíduos e lixo são bastante próximos e muita das vezes entende-se que ambos são sinônimos". E a excessiva produção de embalagens e materiais descartáveis, em função de estímulos para aumentar o consumo, pois a embalagem "valoriza" o produto e os descartáveis ocupam o lugar dos bens duráveis, só aumenta o problema dos resíduos sólidos.

Os resíduos sólidos, de acordo com a Associação Brasileira de Normas Técnicas ABNT-NBR10004/2007, podem ser classificados quanto à origem, tipo de resíduo, composição química e grau de periculosidade, para o homem ou meio ambiente (Quadro 01).

Quadro 01: Classificação, tipo e características dos Resíduos Sólidos

\begin{tabular}{|c|c|c|}
\hline Classificação & Tipo & Características \\
\hline \multirow{5}{*}{ a) Origem } & Industrial & São resíduos gerados em indústrias \\
\hline & Hospitalar & $\begin{array}{l}\text { Resto proveniente de atividades hospitalares e/ou } \\
\text { serviços de saúde (pronto-socorros, enfermarias, } \\
\text { laboratórios de análises clinicas e farmácias). }\end{array}$ \\
\hline & $\begin{array}{l}\text { Comércio/ } \\
\text { Serviços }\end{array}$ & $\begin{array}{l}\text { São os resíduos sólidos domésticos, públicos, } \\
\text { comerciais, nomeadamente os resíduos provenientes } \\
\text { de estabelecimentos comerciais e do setor de } \\
\text { serviços. }\end{array}$ \\
\hline & Agrícola & $\begin{array}{l}\text { São compostos geralmente por embalagem de } \\
\text { produtos químicos usados nas atividades agrícolas, } \\
\text { restos orgânicos (palhas, cascas, estrume, restos de } \\
\text { animais mortos, bagaços e poluentes químicos), } \\
\text { produtos veterinários como seringas, frascos de } \\
\text { medicamentos e etc. }\end{array}$ \\
\hline & Varrição & $\begin{array}{l}\text { Sua composição pode conter folhas e galhos de } \\
\text { árvores, papel, plásticos e restos de alimentos e } \\
\text { animais mortos. Estes resíduos podem ainda ser } \\
\text { denominados de Resíduos Sólidos Urbanos (RSU). }\end{array}$ \\
\hline \multirow[t]{2}{*}{$\begin{array}{l}\text { b) Tipo de } \\
\text { Resíduos }\end{array}$} & Sólido reciclável & $\begin{array}{l}\text { Caracteriza-se pela possibilidade de reutilização, } \\
\text { como por ex.: papel, plástico, metal, alumínio, vidro e } \\
\text { etc. }\end{array}$ \\
\hline & $\begin{array}{lr}\text { Sólido } & \text { não } \\
\text { reciclável (rejeito) }\end{array}$ & $\begin{array}{l}\text { Aquele cuja característica impossibilita sua } \\
\text { reutilização ou reciclagem, ou que ainda, apresentam } \\
\text { caráter de contaminação. }\end{array}$ \\
\hline
\end{tabular}

REVISTA GEONORTE, V.9, N.33, p.111-125, 2018.

DOI: 10.21170/geonorte.2018.V.9.N.33.111.125

(ISSN 2237 - 1419) 


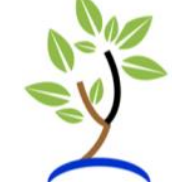

\begin{tabular}{|c|c|c|}
\hline \multirow{2}{*}{$\begin{array}{l}\text { c) Composição } \\
\text { química }\end{array}$} & Orgânico & $\begin{array}{l}\text { As principais fontes de resíduos orgânicos são restos } \\
\text { de alimentos, folhas, gramas, animais mortos, esterco, } \\
\text { papel, madeira, etc. }\end{array}$ \\
\hline & Inorgânico & $\begin{array}{l}\text { São vidros, plásticos e borrachas. Todavia, alguns } \\
\text { desses resíduos apresentam características } \\
\text { recicláveis. }\end{array}$ \\
\hline \multirow{3}{*}{$\begin{array}{l}\text { d) Grau de } \\
\text { periculosidade }\end{array}$} & $\begin{array}{l}\text { Classe I- } \\
\text { Perigosos }\end{array}$ & $\begin{array}{l}\text { São aqueles que, em função de suas características } \\
\text { intrínsecas de inflamabilidade, corrosividade, } \\
\text { reatividade, toxicidade ou patogenicidade apresentam } \\
\text { riscos à saúde pública através do aumento da } \\
\text { mortalidade ou da morbidade }\end{array}$ \\
\hline & $\begin{array}{c}\text { Classe II A - Não } \\
\text { inertes }\end{array}$ & $\begin{array}{l}\text { São os resíduos que podem apresentar características } \\
\text { de combustibilidade, biodegradabilidadeou } \\
\text { solubilidade,com possibilidade de acarretar riscos à } \\
\text { saúde ou ao meio ambiente. }\end{array}$ \\
\hline & $\begin{array}{l}\text { Classe II B - } \\
\text { Inertes }\end{array}$ & $\begin{array}{l}\text { São aqueles quenão tiverem seus constituintes } \\
\text { solubilizados a concentrações superiores aos padrões } \\
\text { de potabilidade de água. }\end{array}$ \\
\hline
\end{tabular}

Fonte: Organizado pelos autores, 2017. Baseado em ABNT 1004/2004

Um dos grandes problemas ambientais da atualidade diz respeito à disposição de resíduos sólidos de origem domiciliar. Tais resíduos, quando dispostos no solo sem tratamento e em grandes quantidades, provocam graves problemas de contaminação ambiental (KIEHL, 1985; JARDIM et al.,1995; ALVES, 1998).

Contudo, corrobora-se que os resíduos sólidos vêm sendo negligenciados tanto pela população quanto pelos legisladores e administradores públicos no que se refere à inexpressiva divulgação de seus efeitos poluidores.

\footnotetext{
As soluções encontradas pelo ser humano para o acondicionamento, coleta, transporte e destino final do lixo apresentam vários inconvenientes e requerem aprimoramento. Da mesma forma que o esgoto, a remoção e o destino final do lixo produzido em zonas de baixa densidade populacional podem ser solucionados individualmente. Nos grandes centros urbanos, porém, é imprescindível a existência de um sistema público eficiente que colete, transporte e deem destino final aos resíduos sólidos (OLIVEIRA; CARVALHO, 2004, p. 90).
}

Muitas cidades procuram meios para destinação final dos resíduos coletados entre eles podemos destacar o aterro sanitário, os vazadouros a céu aberto (conhecidos como lixões), a compostagem, incineração e a reciclagem.

O Instituto Brasileiro de Geografia e Estatística (IBGE), através da Pesquisa Nacional de Saneamento Básico, PNSB -2008 anunciou em 2010 dados em relação à coleta seletiva aderida pelos municípios brasileiros:

Iniciativas para a redução da quantidade de material descartado em aterros, como a coleta seletiva para posterior reciclagem, ainda caminham lentamente. Em 1989 identificou-se a existência de 58 municípios com programas de coleta seletiva de lixo no Brasil. Esse número cresceu para 451 municípios em 2000, e para 994 em 2008, em um universo de 5.564 municípios. 
DISPOSIÇÃO IRREGULAR DOS RESÍDUOS SÓLIDOS URBANOS E SUAS INFLUÊNCIAS NA SAÚDE PÚBLICA NO MUNICÍPIO DE MUCAJAÍ - RR

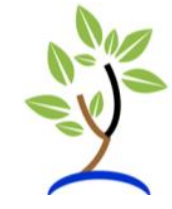

A Lei Federal no 12.305/2010, que orienta para uma nova sistemática na gestão dos resíduos com base em conceitos bastante modernos, com disposições claras, determinou um prazo para que os avanços pretendidos fossem implementados.

Segundo o Panorama dos Resíduos Sólidos no Brasil, em 2014 encerrou o prazo previsto pela Lei para que os municípios tivessem estabelecido a disposição ambientalmente adequada dos rejeitos, o que significa viabilizar ações de aproveitamento e recuperação dos resíduos e encaminhamento da parcela de rejeitos a aterros sanitários, cessando o uso de lixões e aterros controlados. Existem meios ambientalmente corretos para destinação final dos RSU, porém, com custos muitas vezes altíssimos, que as autoridades não estão dispostas a pagar.

\section{Impactos socioambientais decorrentes da disposição dos resíduos sólidos urbanos (RSU)}

Albertin et al. (2010) destacam que os problemas referentes à gestão inadequada dos resíduos não ocorrem somente em grandes centros urbanos, mas também em cidades de médio e pequeno porte que, mesmo produzindo menos resíduos, sofrem com a degradação ambiental, pois representam mais do que poluição, também significam desperdício de recursos naturais e energéticos, entrando na questão do consumismo excessivo, levando-se em conta os produtos descartáveis, o que aumenta a geração dos resíduos, além das questões sociais.

Assim, para que o sistema de limpeza urbana ocorra de forma satisfatória para a população, deve haver um sistema de coleta realizado com regularidade em todos os domicílios.

Dos problemas gerados pela disposição inadequada dos resíduos, podem-se mencionar três pontos relacionados à importância da limpeza:

a) Do ponto de vista sanitário e ambiental, a adoção de soluções inadequadas para o problema dos resíduos faz com que seus efeitos indesejáveis se agravem: os riscos de contaminação do solo, do ar e da água, a proliferação de vetores e de doenças e a catação;

b) Com a maior concentração de pessoas na cidade e o aumento da produção individual de lixo, os locais de tratamento e destinação final devem inspirar maiores cuidados, de modo a não tornarem irreversíveis os danos ambientais decorrentes;

c) E do ponto de vista econômico, a produção exagerada de resíduos sólidos e a disposição final sem critérios apresentam um desperdício de materiais e de energia.

Em condições adequadas, estes materiais poderiam ser reutilizados, diminuindo o consumo dos recursos naturais, a necessidade de tratar, armazenar e eliminar os dejetos, os riscos para a saúde e para o meio ambiente e os gastos com a limpeza e manutenção das vias públicas.

Gouveia (2012) comenta que os vários impactos ambientais decorrentes das diferentes formas de disposição de resíduos sólidos oferecem também riscos 
DISPOSIÇÃO IRREGULAR DOS RESÍDUOS SÓLIDOS URBANOS E SUAS INFLUÊNCIAS NA SAÚDE PÚBLICA NO MUNICÍPIO DE MUCAJAÍ - RR

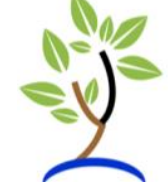

importantes à saúde humana. E a disposição no solo, tanto em lixões como em aterros, constitui uma importante fonte de exposição humana a várias substâncias tóxicas, que estão dispersas no solo e no ar contaminado. Essa situação ocorre tanto quando estão em funcionamento, mas também depois de sua desativação, pois os produtos orgânicos continuam a degradar. Estudos têm indicado que áreas próximas a aterros apresentam níveis elevados de compostos orgânicos e metais pesados e que populações residentes nas proximidades desses locais apresentam níveis elevados desses compostos no sangue.

"O composto obtido do lixo é um adubo orgânico com boas características agronômicas, atuando na melhoria de propriedades físicas, químicas e biológicas do solo" (KIEHL, 1985; NAKAGAWA, 1992).

As medidas tomadas para a solução adequada do problema dos resíduos sólidos têm, sob os aspectos sanitários, objetivos comuns a outras medidas de saneamento: prevenir e controlar doenças a eles relacionadas.

\section{METODOLOGIA}

\section{Localização da área de pesquisa}

A pesquisa foi realizada na área destinada pela Prefeitura do município de Mucajaí para a disposição final dos resíduos sólidos produzidos no município, denominado Lixeira Pública Municipal, localizada nas coordenadas: $02^{\circ} 26^{\prime} 14.19^{\prime \prime} \mathrm{N} / 60^{\circ} 56^{\prime} 25,61$ "O. A área fica a 1,6 km de distância da sede do município de Mucajaí e o acesso ocorre por estrada sem pavimentação (Figura 01).

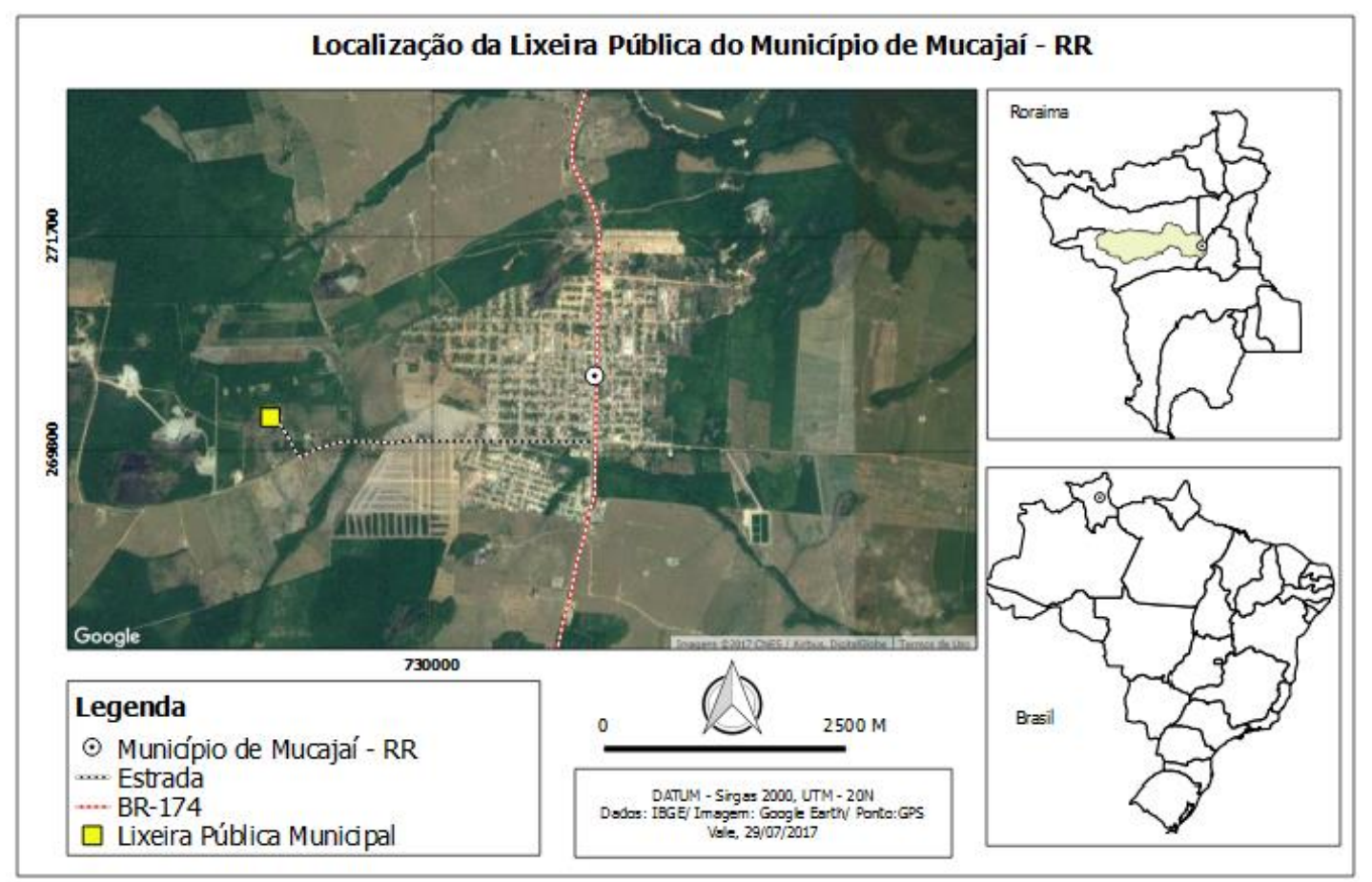

Figura 01: Mapa de localização da Lixeira pública municipal de Mucajaí. Fonte: Autores, 2017. 
DISPOSIÇÃO IRREGULAR DOS RESÍDUOS SÓLIDOS URBANOS E SUAS INFLUÊNCIAS NA SAÚDE PÚBLICA NO MUNICÍPIO DE MUCAJAÍ - RR

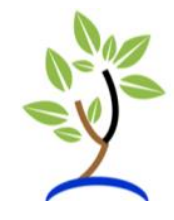

\section{Ferramentas e procedimentos}

O presente estudo é de natureza qualitativa e descritiva, seguindo a percepção de Gil (2009, p.42) que explica "o objetivo primordial de descrever as características de determinada população ou fenômeno".

Para o desenvolvimento da pesquisa foram necessários: a realização de levantamento bibliográfico acerca da temática estudada; o uso de ferramentas tais como: máquina fotográfica digital para registrar a área e o espaço em estudo, Sistema de Posicionamento Global (GPS) para coleta das coordenadas e espacialização dos dados; caderneta de anotações para assinalar todas as informações durante as visitas a campo; visitas às secretarias municipais de Meio Ambiente, à Agência Agropecuária de Roraima (ADERR), de Obras e de Saúde para obter informações em relação à coleta e disposição dos RSU da sede do município de Mucajaí.

Durante a pesquisa foram realizadas visitas in locoentre os meses de setembro e outubro de 2016, para verificação da disposição dos resíduos.Ao final os dados foram tabulados e analisados.

\section{RESULTADOS E DISCUSSÃO}

\section{Impactos ambientais decorrentes da disposição irregular dos resíduos sólidos na área de estudo}

Durante as visitas ao local de estudo, verificou-se que os resíduos sólidos estão sendo depositados de forma inadequada em um lixão a céu aberto, semelhante a algumas cidades, proporcionando diversos impactos ambientais.

Segundo Oliveira Filho (2013) entende-se por impacto ambiental as consequências diretas das ações humanas sobre o ambiente. Já Santos (2004) enfatiza que o impacto ambiental é alteração que compromete o equilíbrio dos ecossistemas naturais ou antropizados.

Nesse sentido, o caminhão que recolhe os resíduos que são produzidos nas residências, deposita os mesmos em qualquer lugar sem os cuidados com o ambiente e com a própria saúde. No local, são despejados todos os tipos de resíduos sólidos coletados e de todas as origens: plásticos, alumínios e metais pesados, hospitalar, carcaças de animais, comerciais, entre outros, causando diversos impactos ao meio natural.

De acordo com informações coletadas informalmente por moradores do entorno do lixão e dados obtidos junto às secretarias já mencionadas anteriormente, o local foi comprado pela Prefeitura Municipal por volta do ano 2000, e desde então funciona como lixão (Figura 02). 
DISPOSIÇÃO IRREGULAR DOS RESÍDUOS SÓLIDOS URBANOS E SUAS INFLUÊNCIAS NA SAÚDE PÚBLICA NO MUNICÍPIO DE MUCAJAÍ - RR
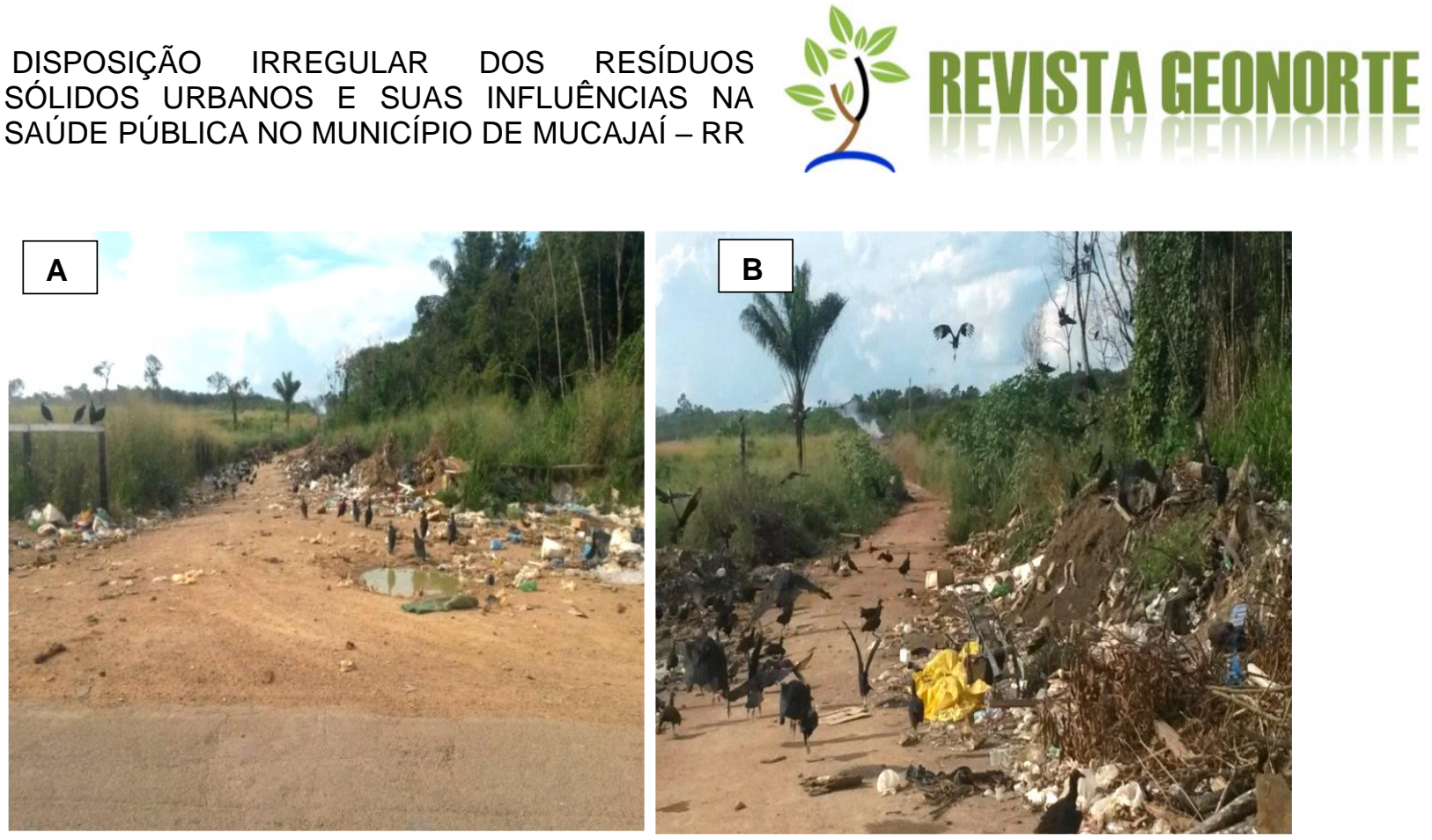

Figura 02: Entrada da lixeira pública municipal.

Fonte: Pesquisa campo, 2016.

$\mathrm{Na}$ entrada do acesso ao lixão é possível verificar os resíduos sólidos dispostos de maneira irregular ao ar livre, sem a separação adequada e restrição de acesso ao local, ocasionando a presença de aves, principalmente urubus; e dentro da área percebeu-se a presença de carcaças de animais mortos que exalam mau cheiro no ambiente. Constata-se também a poluição visual demonstrando a situação precária do local.

Dessa forma, ressalta-se que a Política Nacional dos Resíduos Sólidos (PNRS), Lei no 12.305/2010 esclarece em seu capítulo I, art. 10que: "Incumbe ao Distrito Federal e aos Municípios a gestão integrada dos resíduos sólidos gerados nos respectivos territórios" (BRASIL, 2010). Sendo assim, cada município fica na responsabilidade de implantar projetos que visem à disposição adequada de seus resíduos sólidos.

Segundo informações obtidas na Secretaria Municipal do Meio Ambiente de Mucajaí existem projetos na fase inicial de implantação para se adequar à legislação em relação à disposição dos resíduos. Conforme informações obtidas pela Agência de Defesa Agropecuária de Roraima - ADERR, há monitoramento do local uma vez na semana, com objetivo de retirar animais domésticos como cães (Canis sp.) e gatos (Felis $s p$.) do local.Fato preocupante, pois os animais domésticos podem se tornar hospedeiros de várias doenças que podem ser transmitidas por eles ao retornarem para a casa. Outro fator preocupante é a poluição atmosférica, destacamos: geração de fumaça, fuligem (Figura 03 a e b). 

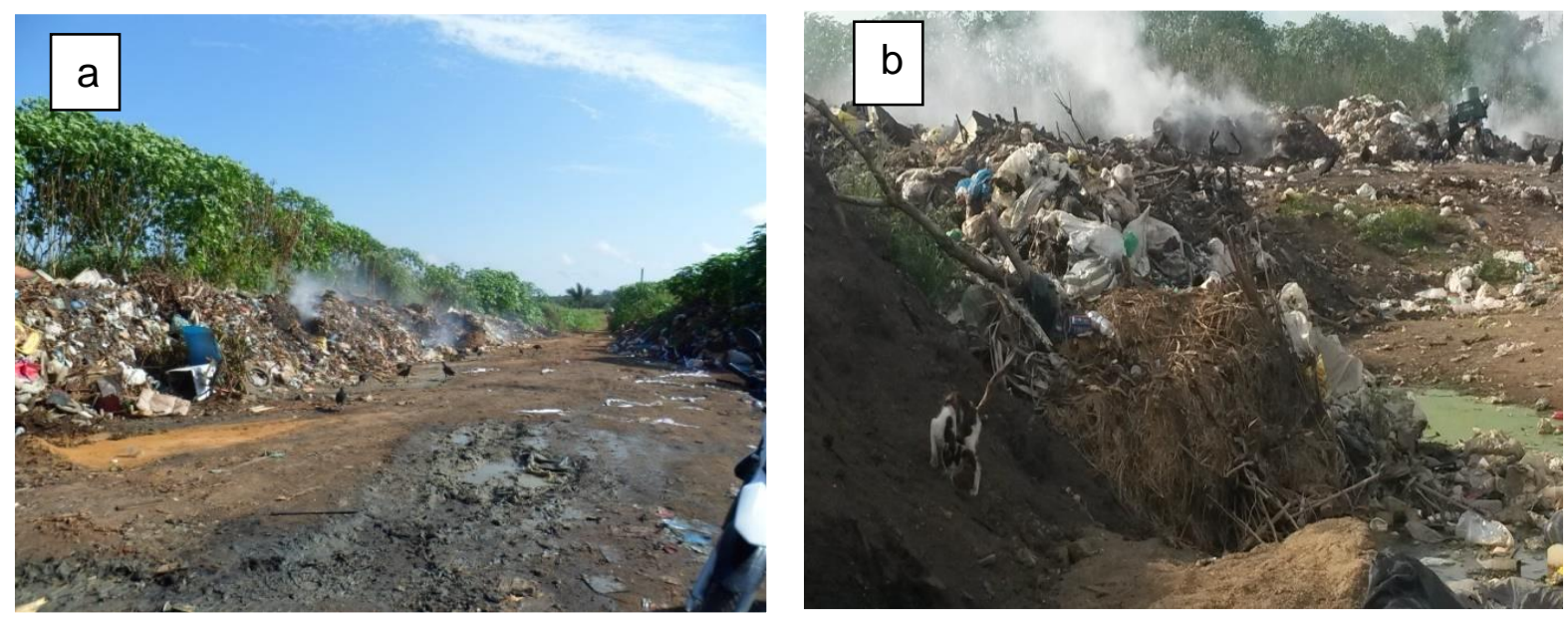

Figura 03: a) queima dos resíduos sólidos; b) animais domésticos e queima dos resíduos. Fonte: Pesquisa de campo, 2016.

\begin{abstract}
A poluição atmosférica por queima de biomassa doméstica é associadaàs doenças respiratórias e cardiovasculares. Entretanto, já se pode associar o aparecimento de neoplasias e asma relacionadas aos efeitos crônicos da contaminação. Os mais vulneráveis nestes casos são as crianças, idosos e as mulheres grávidas, que podem sofrer alterações na função pulmonar. (BRASIL, 2003, p.11).
\end{abstract}

Essa situação pode afetar direta e gravemente a saúde da população, pois a fumaça causada pela queima dos resíduos traz consigo a fuligem que dá origem a uma série de doenças respiratórias. Albuquerque e Strauch (2008) comentam que as consequências da exposição à poluição atmosférica podem ser bem mais graves: os principais efeitos nocivos à saúde humana são problemas oftálmicos, doenças dermatológicas, gastrointestinais, cardiovasculares e pulmonares, além de alguns tipos de câncer. Efeitos sobre o sistema nervoso também podem ocorrer após exposição a altos níveis de monóxido de carbono no ar.

Uma moradora vizinha à lixeira pública municipal relatou que seu esposo faleceu em 2011, vítima de uma infecção pulmonar, causada pela fumaça possivelmente que vem do lixão, comprovada através do atestado de óbito do mesmo, e que ela já recorreu ao fórum, à Prefeitura e à Secretaria Municipal de Meio Ambiente de Mucajaí e nunca obteve nenhuma posição.

Além disso, Gouveia (2012) comenta que a disposição irregular e o processo de queima podem contribuir para o processo de mudanças climáticas, pois a decomposição anaeróbica da matéria orgânica presente nos resíduos gera os gases que produzem o efeito estufa, em especial, o metano $\left(\mathrm{CH}_{4}\right)$.

Os RSUs quando despejados em local inadequado podem trazer uma série de transtornos para toda uma região em volta, além de contribuir consideravelmente para a poluição do meio ambiente. 
DISPOSIÇÃO IRREGULAR DOS RESÍDUOS SÓLIDOS URBANOS E SUAS INFLUÊNCIAS NA SAÚDE PÚBLICA NO MUNICÍPIO DE MUCAJAÍ - RR

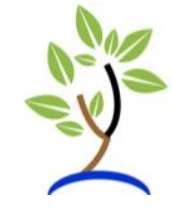

A quantidade de lixo gerada atualmente e os problemas advindos de sua má gestão tem sido abordados com mais seriedade, de forma que o impacto do lixo ao meio ambiente e à saúde, devido a sua destinação final inadequada, causa a contaminação da água e do solo, afetando a vida como um tudo. (CUNHA; CAIXETA FILHO, 2002, p. 143).

Através da fumaça e da fuligem gerados na queima do material disposto, há emissão de partículas e outros poluentes atmosféricos, diretamente pela queima de lixo ao ar livre ou pela incineração de dejetos sem o uso de equipamentos de controle adequados. De modo geral, os impactos dessa degradação estendem-se para além das áreas de disposição final dos resíduos, afetando toda a população.

No entorno da área existem diversos sítios, chácaras e fazendas, nos quaishá criações de animais como bovinos, suínos, ovinos e outros que têm acesso à área. Ressalta-se também a presença de um corpo hídrico que fica a cerca de 200 metros de distância, que pode ter a qualidade da água comprometida devido à proximidade com o lixão, devido ao escoamento e infiltração do chorume no solo. Em uma das casas bem próximas da área a moradora afirma que máquinas da prefeitura invadiram parte de sua propriedade e destruíram plantações para retirar areia, segundo ela, já recorreu aos órgãos responsáveis, mas não obteve nenhuma resposta até o presente momento.

\section{Influência da disposição irregular dos resíduos sólidos urbanos na saúde da população}

Diversos problemas são causados pela disposição irregular dos RSUs, inclusive os que afetam diretamente na saúde da população, Silva et al (2002, p .18) alertam que diferentes microrganismos presentes nos resíduos de serviços de saúde apresentam capacidade de persistência ambiental, entre eles "Mycobacterium tuberculosis, Staphylococcus aureus, Escherichia coli, vírus da hepatite A e da hepatite B".

Como já mencionado anteriormente, os resíduos hospitalares são dispostos de forma irregular, expondo a população a diversos riscos de saúde, devido a presença de animais domésticos no local (Figura 04) que podem servir de hospedeiros de certos organismos que sobrevivem por vários dias no ambiente. 
DISPOSIÇÃO IRREGULAR DOS RESÍDUOS SÓLIDOS URBANOS E SUAS INFLUÊNCIAS NA SAÚDE PÚBLICA NO MUNICÍPIO DE MUCAJAÍ - RR
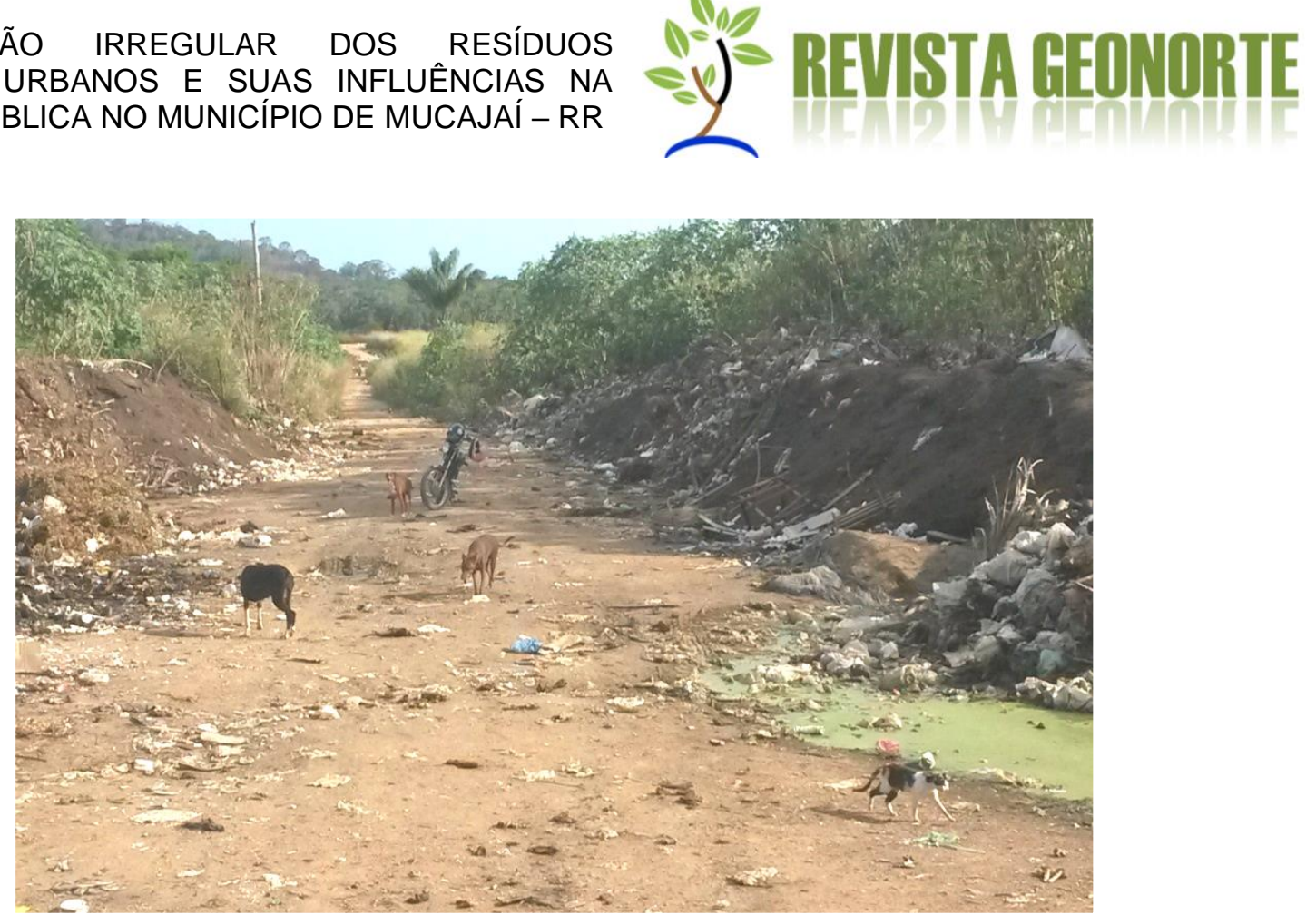

Figura 04: presença de animais domésticos circulando no local. Fonte: Pesquisa de campo, 2016.

Bidone (2001) destaca o tempo de sobrevivência de alguns microrganismos que podem proliferar em ambientes propícios como é um caso do lixão, como mostra no quadro 02.

\begin{tabular}{|c|c|}
\hline \multicolumn{2}{|c|}{ Quadro 02: Tempo de sobrevivência de alguns organismos en } \\
\hline Organismo & Tempo de sobrevivência \\
\hline \multicolumn{2}{|c|}{ Bactérias } \\
\hline Coliformes fecais & 35 dias \\
\hline Leptospirainterrogans & 15-43 dias \\
\hline Mycobactelumtubeculosis & 150-180 dias \\
\hline Salmonellathyphi & $29-70$ dias \\
\hline Salmonellaparathyphi & 29-70 dias \\
\hline Salmonellasp. & 29-70 dias \\
\hline Shigella & 2-7 dias \\
\hline \multicolumn{2}{|c|}{ Vírus } \\
\hline Enterovírus & 20-70 dias \\
\hline Pólio vírus - pólio tipo I & 20-170 dia \\
\hline Vírus da hepatite B (HBV) & Algumas semanas \\
\hline Vírus da imunodeficiência humana & 3-7 dias \\
\hline
\end{tabular}

Fonte: Bidone, 2001, p.154.

Atentamos também para a geração de vetores dentre os quais se destacam: moscas (Musca domestica), baratas (Supellalongipalpa), ratos (família muridae) e principalmente o mosquito Aedes aegypt, causador da dengue, xincungunha, e o 
DISPOSIÇÃO IRREGULAR DOS RESÍDUOS SÓLIDOS URBANOS E SUAS INFLUÊNCIAS NA SAÚDE PÚBLICA NO MUNICÍPIO DE MUCAJAÍ - RR

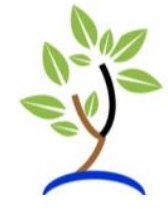

poderoso Zíca vírus, o mosquito Anopheles, causador da malária, e vários outros transmissores de diversas doenças.

Conforme dados da Secretaria de Vigilância em Saúde do município, no ano de 2016 foram 7 casos confirmados de dengue, 83 casos inconclusivos, e 84 casos confirmados de malária na sede, o que possivelmente pode estar associado à lixeira pública municipal.

A Assessoria de Comunicação Social do Ministério Público de Roraima (MPERR, 2012) informou que firmou o termo de ajustamento de conduta (TAC) com a Prefeitura de Mucajaí para construção de um aterro sanitário. Segundo o documento, a administração municipal tem 60 dias para cumprir os prazos previstos no acordo, sob pena de sanções administrativas, além de multa diária no valor de $R \$ 350,00$.

O TAC foi celebrado por meio da Promotoria de Mucajaí e prevê a construção e instalação de aterro sanitário, inclusive a realização do estudo prévio de impacto ambiental. A prefeitura deve ainda elaborar plano de recuperação de áreas degradadas, relativo ao lixão, e projeto de Educação Ambiental e de divulgação do empreendimento, bem como a coleta seletiva de resíduos. Ainda que a prefeitura tem 30 dias para isolar a área, bem como a fiscalização e controle de veículos e pessoas no local.

Foi dado prazo de 60 dias para construção de valas para desviar o curso do chorume oriundo dos resíduos que estejam atingindo nascentes, igarapés, açudes ou qualquer outro corpo hídrico, localizados a menos de 200 metros do depósito dos resíduos. No entanto, até o presente momento constatou-seque a prefeitura municipal não cumpriu o acordo, e que os resíduos encontram-se dispostos irregularmente no lixão a céu aberto, no perímetro urbano, causando vários impactos ambientais na área e trazendo incômodos à população local.

Por outro lado, se os resíduos tivessem destinação correta, conforme a consolidação da Política Nacional de Resíduos sólidos que preconiza a implantação de aterros sanitários e a consolidação das políticas de Educação Ambiental junto à comunidade em geral, as cidades teriam um nível de poluição bem menor e os aspectos sanitários seriam favoráveis às populações.

\section{CONCLUSÃO}

Nesta pesquisa constatou-se que a cidade de Mucajaí não está de acordo com a Lei12.305/2010, pois além de enfrentar outros problemas sociais e de infraestrutura visivelmente expostos, é possível observar resíduos sólidos frente às casas, entulhos e galhadas nas ruas que, quando coletados, são despejados no lixão municipal sem nenhum tipo de cuidado, causando vários transtornos aos moradores que vivem no entorno da área. No decorrer da pesquisa constatou-se que essa disposição irregular vem atraindo vários animais domésticos para dentro do lixão. Os agentes da ADERR fazem a monitoria, no entanto, os animais são expulsos para outras áreas que, segundo moradores, vão procurar abrigo em suas propriedades, causando 
DISPOSIÇÃO IRREGULAR DOS RESÍDUOS SÓLIDOS URBANOS E SUAS INFLUÊNCIAS NA SAÚDE PÚBLICA NO MUNICÍPIO DE MUCAJAÍ - RR

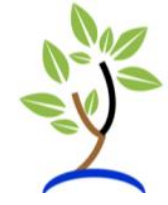

preocupação referente à saúde, pois estes animais se tornam hospedeiros de possíveis patógenos causadores de doenças e a Fundação Estadual de Meio Ambiente e Recursos Hídricos de Roraima - FEMARH efetiva as multas decorrentes da disposição irregular.

Outra preocupação é com a queima dos resíduos no local, que incomodam e também podem causar algum tipo de infecção pulmonar, e outros casos de doenças que acometam o sistema respiratório como um todo.

Através da pesquisa foi possível observar os diversos impactos ambientais que a lixeira pública está causando na sede do município, prejudicando o solo, a água e o ar, além de acometer a saúde da população. Então é preciso que as autoridades, junto à população, busquem medidas urgentes no âmbito da saúde pública para combatêlos ou, pelo menos, que possam minimizar os impactos.

\section{REFERÊNCIAS}

ALBERTIN, R.M. et al. Avaliação e Diagnóstico do Gerenciamento dos Resíduos Sólidos Urbanos no Município de Cianorte-PR, 2010. Disponível em: <http://pluris2010.civil>. Acesso em: 06ago. 2018.

ABRELPE - ASSOCIAÇÃO BRASILEIRA DE EMPRESAS DE LIMPEZA PÚBLICA E RESÍDUOS ESPECIAIS. Panorama dos resíduos sólidos no Brasil, 2016. São Paulo, SP: ABRELPE, 2017. ISSN: 2179-8303. 64p. Disponível em:< http://www.abrelpe.org.br/Panorama/panorama2013.pdf>. Acesso em 21 ago. 2017

ALBUQUERQUE, P. P.; STRAUCH, M. Resíduos: como lidar com os recursos naturais. Editora: OIKOS, 2008.

ALVES, W.L. Compostagem e vermicompostagem no tratamento de lixo urbano. 2ed. Jaboticabal: FUNEP, 1998.

ASSOCIAÇÃO BRASILEIRA DE NORMAS TÉCNICAS - ABNT. Resíduos sólidos classificação. NBR-1004/2004. Revisada. Rio de Janeiro, 2007.

BARROS, R. T. de V. et al. Manual de Saneamento e Proteção Ambiental para os Municípios. Volume 2. Escola de Engenharia da UFMG / DESA / FEAM / GTE. Belo Horizonte. 1995

BRASIL. Ministério da Educação e Cultura. FNDE. Ciência Hoje das Crianças, ano 15, n. 131, p.11, 2003.

BRASIL. Política Nacional de Resíduos Sólidos: lei no 12.305 de 02 de agosto de 2010.

BIDONE, F. R. A. (Coord.) Resíduos sólidos provenientes de coletas especiais: reciclagem e disposição final. Projeto PROSAB. Rio de Janeiro: ABES, 2001. 
DISPOSIÇÃO IRREGULAR DOS RESÍDUOS SÓLIDOS URBANOS E SUAS INFLUÊNCIAS NA SAÚDE PÚBLICA NO MUNICÍPIO DE MUCAJAÍ - RR

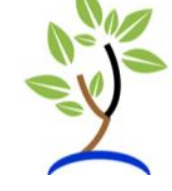

COELHO, S. M. M. Direito e educação ambiental: caminhos para conciliar preservação e desenvolvimento. Dissertação (mestrado) - Pontifícia Católica de Goiás, faculdade de Direito/GO, 2012.

CUNHA V., CAIXETA FILHO J. V. Gerenciamento da coleta de resíduos urbanos: estruturação e aplicação de modelo não linear de programação por metas. GESTÃO E PRODUÇÃO, p. 143, ago. 2002.

GRANZIERA, M. L. M. Direito Ambiental. São Paulo: Atlas, 2009.

GIL, A. C. Como elaborar projetos de pesquisa. 4ed. São Paulo: Atlas, 2009.

GOUVEIA, N. Resíduos sólidos urbanos: impactos socioambientaise perspectiva de manejo sustentável com inclusão social. Ciência \& Saúde Coletiva, 17 (6), 2012. p.15031510. Disponível em: <https://www.scielosp.org/pdf/csc/2012.v17n6/1503-1510/pt\#top>. Acesso em: 02 de jul. 2018.

JARDIM, N.S.; WELLS, C.; PRANDINI, F.L.; ALMEIDA, M.L.O E MANO, V.G.T. Lixo municipal: Manual de gerenciamento integrado. São Paulo, IPT/CEMPRE, 1995.

KIEHL, E.J. Fertilizantes orgânicos. Piracicaba, CERES, 1985.

MINISTÉRIO PÚBLICO DO ESTADO DE RORAIMA - MPERR. Assessoria de comunicação social do ministério público de Roraima. 2012. Disponível em <http://www.ascom@mp.rr.gov.br.> Acesso em 10 nov.2016.

NAKAGAWA, J. Compostagem: obtenção e uso. ENCONTRO SOBRE MATÉRIAORGÂNICA DO SOLO - problemas e soluções., 1., Botucatu, 1992. Anais... Botucatu, FEPAF, 1992. p.159-187.

OLIVEIRA, N. A. S. A percepção dos resíduos sólidos (lixo) de origem domiciliar no Bairro Cajuru, Curitiba-PR: um olhar reflexivo a partir da educação ambiental. 160f. Tese (Mestrado em Geografia). Universidade Federal do Paraná. Curitiba, 2006.

OLIVEIRA FILHO, G.R. Uma breve reflexão sobre o conceito de impacto ambiental. CES Revista, v.27, n.1, Juiz de Fora-MG, 2013. p. 15-28. Disponível em: <https://www.cesjf.br/revistas/cesrevista/edicoes/2013/Artigo\%2001.pdf>. Acesso em: set. 2018.

SILVA, A. C. N. et. al. Critérios adotados para seleção de indicadoresde contaminação ambiental relacionados aos resíduos sólidosde serviços de saúde: uma proposta de avaliação. 25 CONGRESSO INTERAMERICANO DE ENGENHARIA SANITÁRIA E AMBIENTAL. Anais... 2002. 
DISPOSIÇÃO IRREGULAR DOS RESÍDUOS SÓLIDOS URBANOS E SUAS INFLUÊNCIAS NA SAÚDE PÚBLICA NO MUNICÍPIO DE MUCAJAÍ - RR

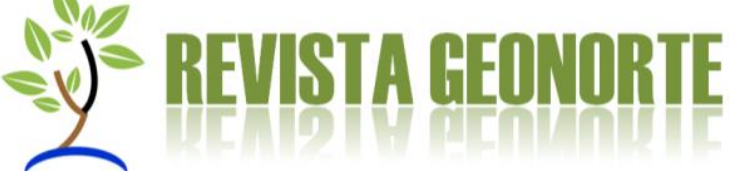

TENÓRIO, J.A.S.; ESPINOSA C.R.Controle Ambiental de Resíduos. In: PHILIPPI Jr, A.; ROMÉRO, M.A.; BRUNA, G.C. (Ed.). Curso de Gestão Ambiental. Barueri, SP: Manole, 2004. p. $155-212$. 